\title{
Integration of Clinical Examination, Self-Report, and Hair Ethyl Glucuronide Analysis for Evaluation of Patients With Alcoholic Liver Disease Prior to Liver Transplantation
}

Progress in Transplantation 2016, Vol. 26(I) 40-46 (C) 2016, NATCO. All rights reserved. Reprints and permission: sagepub.com/journalsPermissions.nav DOI: I0.II77/I5269248I6632I20 pit.sagepub.com (S)AGE

\author{
Mingo Beckmann, PhD', Georgios Paslakis, MD², \\ Michael Böttcher, PhD $^{3}$, Anders Helander, PhD $^{4}$, \\ and Yesim Erim, $M D^{1,2}$
}

\begin{abstract}
Context: A large proportion of liver transplants (LTXs) are performed due to alcoholic liver disease (ALD) in the final stage of organ insufficiency. In order to list patients for LTX, transplant centers commonly require 6 months abstinence from alcohol. However, significant differences have been reported between alcohol intake as indicated by self-report and biochemical markers of alcohol. Objective: In the present study, the usefulness of ethyl glucuronide analysis in hair (hETG) was examined during the evaluation procedure before listing patients with ALD for an LTX. Design: Cross-sectional survey. Setting: Psychosomatic evaluation. Patients: Seventy patients with ALD prior to listing for an LTX. Interventions: According to clinical assessment before listing patients with ALD $(n=233)$ for an LTX, hETG analysis was only performed in the patients who were assumed to deny or underreport their alcohol consumption $(n=70)$. Main Outcome Measures: The analysis of hETG by liquid chromatography-mass spectrometry, clinical interview. Results: By hETG analyses, 27 (38.6\%) of the 70 patients tested positive for ongoing alcohol consumption. Conclusions: Selective use of hETG based on the clinical interview rather than widespread screening is a possible way to detect excessive alcohol consumption in patients with ALD in the transplant setting. The primary evaluation of a patient's situation in its entirety should remain the superordinate standard procedure. An interdisciplinary approach to transplant candidates with an ALD is asked for.
\end{abstract}

\section{Keywords}

alcohol liver disease, hair ethyl glucuronide, liver transplantation, cirrhosis, psychosomatic evaluation

\section{Introduction}

Liver transplantation (LTX) is an accepted and common treatment option for alcoholic liver disease (ALD) showing favorable outcome and high long-term survival rate. ${ }^{1,2}$ Between $30 \%$ and $50 \%$ of LTXs are currently conducted because of ALD in the final stage of organ insufficiency. ${ }^{3,4}$ In order to list patients with ALD for LTX, transplant centers commonly require a 6month abstinence from alcohol not only because ongoing alcohol intake may have a dramatic impact on graft survival but also because the need for LTX can sometimes be delayed or may no longer be necessary at all..$^{5-7}$

Patients with ALD may have severe difficulty to meet abstinence without appropriate support. Patients in need of LTX may also deny or underreport their true alcohol intake, fearing they would otherwise not be listed or transplantation be delayed. Indeed, random blood alcohol (ethanol) testing was reported to detect concealed alcohol intake in patients with
ALD awaiting LTX $^{8}{ }^{8}$ Erim et $\mathrm{al}^{9}$ underscored the uncertainty of self-report data and also the low sensitivity of alcohol testing as ways to disclose recent drinking in the transplantation setting prior to listing and instead demonstrated the value of using

\footnotetext{
'Department of Psychosomatic Medicine and Psychotherapy, University Hospital of Essen, Essen, Germany

${ }^{2}$ Department of Psychosomatic Medicine and Psychotherapy, FriedrichAlexander-Universität Erlangen-Nürnberg (FAU), University Hospital of Erlangen, Germany

${ }^{3}$ MVZ Labor Dessau GmbH, Dessau-Roßlau, Germany

${ }^{4}$ Department of Laboratory Medicine, Karolinska Institutet and Karolinska University Laboratory, Stockholm, Sweden

Corresponding Author:

Yesim Erim, Department of Psychosomatic Medicine and Psychotherapy, Friedrich-Alexander University, Erlangen-Nürnberg Schwabachanlage 6, 91054 Erlangen, Germany.

Email: yesim.erim@uk-erlangen.de
} 
sensitive and specific biochemical alcohol markers such as urinary ethyl glucuronide (ETG). The significant discrepancy between alcohol consumption as indicated by self-report and alcohol biomarkers has also been highlighted by others. ${ }^{10}$

Using methanol in blood as alcohol biomarker, about onethird of blood samples collected during the evaluation process for LTX listing tested positive for current alcohol intake. ${ }^{11}$ Likewise, half of the transplant candidates denying alcohol consumption within the last 6 months tested positive for at least 1 alcohol biomarker, including novel, sensitive, and specific tests such as ETG in urine and ETG in hair (hETG). ${ }^{12}$ Also when placed on the waiting list for LTX, relapse rates of $15 \%$ to $25 \%$ have been reported among patients with ALD. ${ }^{13}$ Although the above-mentioned results underline the necessity of introducing sensitive and specific objective measures of recent alcohol consumption in the transplantation setting, there is no established consensus regarding how abstinence should be determined (ie, which biomarker), in which patients (eg, all patients or selected "high-risk" patients), how often (single or repeated measures), or by whom (transplantation or psychosomatic medicine specialists or liaison psychiatrists).

In the present study, hETG analysis was initiated by psychosomatic medicine specialists during the evaluation procedure, before listing patients with ALD for LTX. The analysis of hETG was only performed in the patients who were assumed to deny or underreport their alcohol consumption, according to clinical assessment. This procedure could be a routine way of proceeding with patients having ALD in the transplantation setting.

\section{Materials and Methods}

\section{Participants}

From January 2011 to December 2012, 501 patients with terminal liver disease have undergone a psychosomatic evaluation in the Department of Psychosomatic Medicine and Psychotherapy at the University Hospital of Essen, Germany, before placed on the waiting list for an LTX. A total of 233 patients had an ALD diagnosis, whereas 200 (39.9\%) were diagnosed with alcohol addiction and 33 (6.6\%) with harmful alcohol use, according to the International Classification of Diseases, Tenth Revision (ICD-10) ${ }^{14}$ (Figure 1). The study was approved by the local ethics committee, and all patients gave written informed consent for participation.

\section{Psychosomatic Evaluation}

At the initial screening visit, patients with an ALD were interviewed by a physician for psychosomatic medicine or an experienced psychologist. With regard to alcohol abstinence status and risk of alcohol intake or recidivism, all patients were evaluated for their suitability as transplant recipients on the basis of a clinical/psychosomatic examination. The information gathered included (1) length of self-reported alcohol abstinence preceding the visit (more or less than 6 months) and (2) risk factors for alcohol intake or recidivism such as a diagnosis of alcohol dependence (vs harmful alcohol use), lack of understanding of the situational conditions and motivations of alcohol abuse, lack of participation in previous therapy programs or Anonymous Alcoholics groups, lack of coping skills and social support, and an alcohol use disorder of first-degree biological relatives or cohabitating spouses.

In detail, patients were asked to specify their current drinking behavior and their alcohol intake during 6 months prior to the screening visit. Patients with ongoing heavy alcohol use were referred to inpatient treatment. Patients with a moderate risk of relapse were supported in a manualized group therapy. ${ }^{15}$ Patients who admitted to alcohol intake but whose statements gave reason for distrust with regard to frequency and/or quantity of consumption were called "minimizers." Those patients who denied any alcohol intake despite the presence of significant risk factors were called "noncredible negators."

Both minimizers and noncredible negators were asked to provide a hair sample for measurement of hETG. Next to the obvious risk factors that might have been sustaining drinking behaviors, also information on alcohol intake provided by others (eg, cotreating health professionals) that disagreed with patient self-reports resulted in hair sampling for hETG testing. In addition to the clinical evaluation regarding alcohol intake, patients were judged with regard to their psychosocial functioning according to the transplant evaluation rating scale (TERS). The TERS assesses coping strategies, compliance to therapeutic recommendations, degree of social support, and health-related behavior. ${ }^{16}$ The German translation of TERS shows good interrater reliability. ${ }^{17,18}$

\section{Ethyl Glucuronide Measurement in Hair}

Detection of ETG in the scalp hair of patients (hETG) allows monitoring of abstinence over a retrospective period of 3 (or even for up to 6) months, with each $1-\mathrm{cm}$ segment reflecting alcohol consumption over a period of approximately 1 month. At least 3-cm head hair was collected from the posterior vertex and cut as close as possible to the scalp. Hair strands were aligned with twine and stored in an envelope at room temperature until analysis. From the proximal $3 \mathrm{~cm}$ of hair, at least 50 $\mathrm{mg}$ were processed for liquid chromatographic-mass spectrometric (LC-MS/MS) analysis. The applied analytical method is fully validated and accredited according to forensic guidelines and DIN EN ISO 17025. ${ }^{19}$

According to international standards for hETG measurement, ${ }^{20}$ the following cutoffs were applied: $<7 \mathrm{pg}$ ETG/mg hair, abstainers/rare drinking; 7 to $30 \mathrm{pg} / \mathrm{mg}$, occasional alcohol consumption ( $>10 \mathrm{~g}$ ethanol/day); and $>30 \mathrm{pg} / \mathrm{mg}$, chronic alcohol intake ( $>60 \mathrm{~g}$ ethanol/day). The hETG concentrations $\geq 7 \mathrm{pg} / \mathrm{mg}$ were regarded "positive."

\section{Data Analysis and Statistical Methods}

Data were analyzed using the software SPSS for Microsoft Windows. For descriptive analysis, data were expressed as 


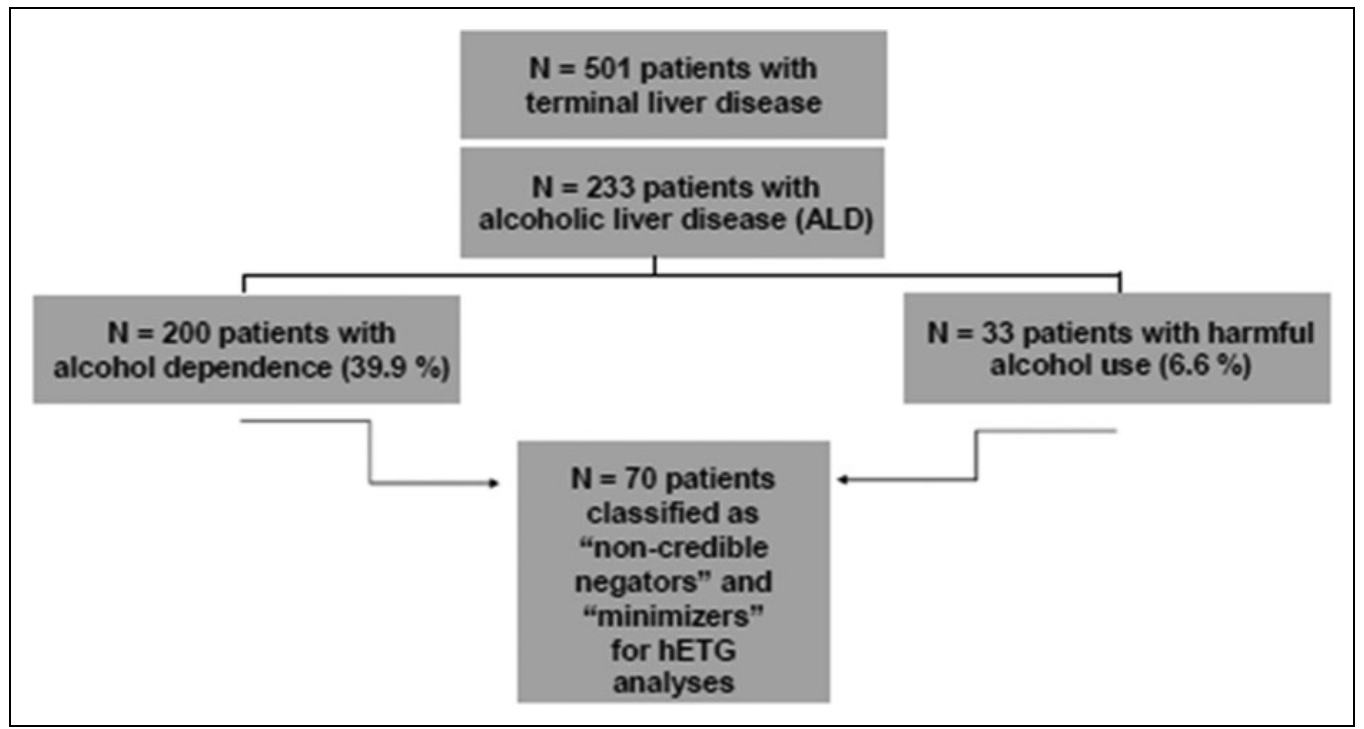

Figure I. A total of $\mathrm{N}=50 \mathrm{I}$ patients with terminal liver disease were evaluated for eligibility prior to listing for a liver transplant. Of these, $\mathrm{n}=$ 70 patients were included for ethyl glucuronide in hair (hETG) analyses in the present study. For more details, see main text (Material and Methods).

Table I. Demographic Data of the Participants in the Present Study.

\begin{tabular}{lc}
\hline Demographics & \\
\hline Age, years & $M=49.93$, SD $=8.74$ \\
Range & $30-68$ \\
Sex & \\
$\quad$ Female & $41(58.6 \%)$ \\
$\quad$ Male & $29(41.4 \%)$ \\
Family & \\
$\quad$ Single & $15(21.4 \%)$ \\
$\quad$ Married & $32(45.7 \%)$ \\
$\quad$ Separated/divorced & $23(32.9 \%)$ \\
Education & \\
$\quad$ Without degree & $6(8.6 \%)$ \\
Secondary modern school qualification & $27(38.6 \%)$ \\
Secondary school certificate & $20(28.6 \%)$ \\
High-school diploma & $17(24.3 \%)$ \\
\hline
\end{tabular}

Abbreviations: M, mean, SD, standard deviation.

mean $(\mathrm{M})$ value and standard deviation (SD). Mean differences in variables among subgroups were compared by $\chi^{2}$ test, $t$ test for independent variables, and Mann-Whitney $U$ test. Pearson and Spearman correlations were conducted to test the linear relationship between variables. Analysis of variance was applied to test the main effects of confounders such as gender, age, or educational level. For all tests, a significance level of $P<.05$ was predetermined.

\section{Results}

\section{Patient Sample}

In total 70 LTX candidates with an ALD classified as either minimizers or noncredible negators of their alcohol intake underwent hETG testing, in order to confirm or disprove the
Table 2. Distribution of Psychiatric Diagnoses Among the Participants of the Study According to the International Classification of Diseases, Tenth Revision (WHO, ICD-I0).

\begin{tabular}{lc}
\hline Psychiatric Diagnoses According to ICD-I0 & \\
\hline Mental and behavioral disorders due to psychoactive substance use \\
F I0.I Abuse of alcohol & I8 (25.7\%) \\
F I0.2 Dependence of alcohol & $52(74.3 \%)$ \\
F II.2 Dependence of opioids & I \\
F I2.I Abuse of cannabinoids & 4 \\
F I3.I Abuse of sedative hypnotics & 8 \\
F I7.I Abuse of tobacco & 3 \\
F I7.2 Dependence of tobacco & I \\
F 19.2 Dependence of multiple drugs & 4 \\
Mood [affective] disorders & I \\
F 32.0 Mild depressive episode & I \\
F 33.4 Recurrent depressive disorder, currently in \\
remission
\end{tabular}

clinical impression and/or self-report. None of the patients refused to provide a hair sample, and all samples collected were appropriate for LC-MS analysis. The M age of the patients was 49.9 years (SD 8.7), and $58.6 \%$ were females. Demographic data are shown in Table 1. 


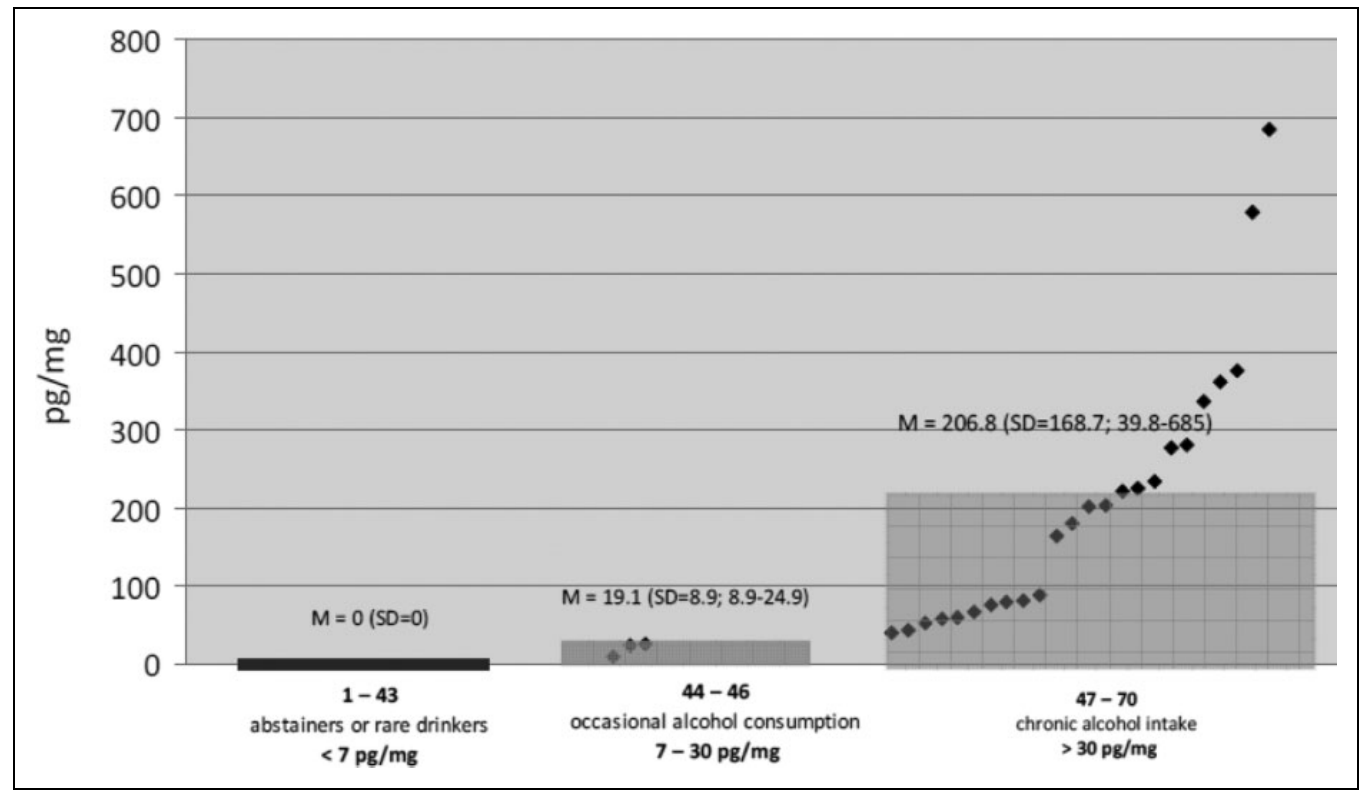

Figure 2. Graphic display of the distribution of ethyl glucuronide in hair (hETG) results in $n=70$ patients with alcoholic liver disease (ALD) awaiting liver transplantation.

Table 3. A Total of 70 Patients With ALD Awaiting a Liver Transplant Who Were Thought to Be Active Alcohol Consumers Were Asked About Their Abstinence of Alcohol During the Last 6 Months. ${ }^{a}$

\begin{tabular}{lccc}
\hline & \multicolumn{2}{c}{ Have You Abstained From Alcohol During the Last 6 Months? } \\
\cline { 2 - 4 } & Noncredible Negators (64.3\%), $\mathrm{n}=45$ & Minimizers (35.7\%), $\mathrm{n}=25$ & $\mathrm{n}=1 \mathrm{I}$ \\
\hline hETG positive & $\mathrm{n}=16(35.6 \%)$ & $\mathrm{n}=14$ & 27 \\
hETG negative & $\mathrm{n}=29(64.4 \%)$ & 43 \\
\hline
\end{tabular}

Abbreviations: ALD, alcoholic liver disease; hETG, ethyl glucuronide in hair.

${ }^{a}$ Patients self-reports were reappraised with analyses of hETG (for details, please see main text).

For the 70 patients, a total of 100 psychiatric diagnoses (according to $I C D-10$ ) were given. The most frequent diagnoses were alcohol addiction ( $\mathrm{F} 10.2 ; \mathrm{n}=52)$ and harmful alcohol use $(\mathrm{F} 10.1 ; \mathrm{n}=18)$. Further diagnoses are shown in Table 2.

\section{Main Results for the Entire Cohort}

According to the international standard cutoffs for hETG, 43 (61.4\%) patients showed hETG values $<7 \mathrm{pg} / \mathrm{mg}$ and were regarded as abstainers or rare drinkers, $3(4.3 \%)$ patients exhibited hETG values in the range 7 to $30 \mathrm{pg} / \mathrm{mg}$, pointing toward occasional or regular moderate alcohol consumption, and 24 (34.3\%) patients showed values $>30 \mathrm{pg} / \mathrm{mg}$, suggesting chronic heavy alcohol intake. The M hETG level in the chronic alcohol consumers was $206.8 \mathrm{pg} / \mathrm{mg}(\mathrm{SD}=168.7)$. These results are presented in Figure 2.

\section{Results for the Clinical Subgroups}

According to the clinical classification, 45 of the 70 patients were clinically classified as noncredible negators and 25 as minimizers of their alcohol intake during the 6-month period preceding the screening visit. A total of 27 (38.6\%) patients tested positive for $\mathrm{hETG}(\geq 7 \mathrm{pg} / \mathrm{mg})$. In the noncredible negators, 16 tested positive for hETG, as did 11 of the minimizers.

On the other hand, 24 patients who were considered noncredible negators based on clinical assessment and the presence of risk factors tested negative for hETG $(<7 \mathrm{pg} / \mathrm{mg})$. These patients were called credible negators with regard to the $\sim 3$ month period covered by hETG analysis. Similarly, 14 minimizers, who had admitted not having abstained from alcohol during the preceding 6 months, tested negative for hETG, putatively because the $\mathrm{hETG}$ values only reflected alcohol intake in the previous $\sim 3$ months. The results of hETG analysis for each subgroup are displayed in Table 3.

\section{Values of hETG and Demographic Data}

Significantly more women than men tested positive for hETG $\left(\chi^{2}=12.8 ; P<.001\right)$. Furthermore, the hETG-positive and hETG-negative patients differed significantly with regard to age $(t=-1.97 ; P=.05)$ and level of education $\left(\chi^{2}=10.71\right.$; $P=.01)$, with younger and higher educated patients exhibiting 
more positive hETG tests. With regard to the clinically defined subgroups, there turned out to be significantly more female minimizers $\left(\mathrm{n}=14 ; \chi^{2}=9.03 ; P=.003\right)$.

\section{Discussion}

Minimizing or denying alcohol consumption by patients with an ALD in the LTX setting is a well-known problem. It is the fear of patients of getting rejected from the transplant waiting list paired with their difficulty to achieve the required complete abstinence that motivates them to being dishonest in selfreports. In the present work, patients with an ALD were evaluated for eligibility prior to listing for an LTX. The evaluation procedure with regard to the consumption of alcohol was undertaken by an experienced psychologist or an expert physician in psychosomatic medicine and included self-reports of abstinence or drinking behaviors, as well as the identification of collateral risk factors of alcohol intake. Besides, based primarily on clinical judgement of the presence of risk factors for alcohol intake or recidivism, hETG concentrations were determined in all those cases in which patients were thought to be negating or minimizing their alcohol intake. This has led to a total of $\mathrm{n}=70$ patients being included in the study of $\mathrm{hETG}$ measures. As a main result, $\mathrm{n}=27$ patients $(38.6 \%)$ were tested positive for ongoing alcohol consumption. Our results support the findings of several previous studies that have identified the ongoing alcohol intake in patients with an ALD both during the evaluation prior to listing for LTX and while awaiting an LTX as a relevant clinical problem. This problem needs to be specifically addressed.

Although alcohol intake in transplant candidates with an ALD prior to listing for LTX is a relevant problem, up to now there is no guideline or expert consensus determining an appropriate approach at the time of initial presentation. Different biological markers for alcohol intake or their combinations have been tested in the transplant setting in patients with an ALD, and while some authors have chosen to test patients in a random manner, ${ }^{8}$ nonselectively ${ }^{12}$ or on a voluntary basis, ${ }^{9}$ here it was chosen to carry out controls in just a selection of patients. The advantage of testing all patients without exception is that it allows a maximum disclosure of alcohol consumption and that it delivers an objective measure for further clinical decisions. Having applied this methodology, transplant candidates denying alcohol consumption within the last 6 months had a positive hETG result in $83 \%$ of the cases. ${ }^{12}$ The disadvantage of such an approach from the perspective of psychosomatic medicine lies in the implication that the assessment of a biological parameter may be placed in the center of decision making, thus, in a sense, devaluating the significance of the clinician's assessment of meaningful circumstances. In contrast, the present approach places the patient's clinical assessment in the center of the evaluation process, and the assessment of hETG as a biological marker for alcohol intake is performed in order to gain additional information as the need arises. Certainly, this is just one conceivable approach to patients with ALD in the transplantation setting and it appears to be more sound than random testing or testing on a voluntary basis. The disadvantage of this approach is, obviously, that it may not capture all cases of alcohol intake unerringly.

On the other hand, the assessment of biological markers of alcohol intake are not unerring themselves, and false positive results in the transplantation setting that may wrongly exclude patients from LTX are a serious concern. The sensitivity and specificity of each of the different available markers of alcohol intake (such as the direct detection of ethanol in blood or breath or markers such as the carbohydrate-deficient transferrin [CDT] or urinary ETG) have been published and discussed elsewhere. ${ }^{21-23}$ Due to their different detection windows, the use of each of these markers may be justified in a different setting and pursuing a different goal. ${ }^{24}$ Breath analyses may be used in therapeutic settings to control sobriety. Blood tests may be useful for a physician's evaluation of patients during routine examinations. The CDT is a marker reflecting alcohol intake in the preceding 1 to 4 weeks, ${ }^{25}$ but it is inappropriate for the detection of low to moderate alcohol intake, because a daily consumption of 60 to $80 \mathrm{~g}$ ethanol for a minimum of 7 to 10 days is required for a positive test result. Finally, ETG remains positive in the urine for up to 80 hours depending on the amount of alcohol intake and allows detection of very small amounts of ethanol (eg, $<5 \mathrm{~g})$.

With regard to hETG, sensitivity and specificity rates have been identified as being high, ${ }^{26-30}$ and some authors have claimed that hETG testing may be appropriate to disprove abstinence rather than proving it. ${ }^{28,31}$ Daily alcohol intake correlates well with hETG concentrations, ${ }^{32}$ and international cutoff values have been set. ${ }^{33}$ Although hETG concentrations between 7 and $30 \mathrm{pg} / \mathrm{mg}$ should be interpreted with caution, there is great certainty that patients showing high hETG concentrations $(>30 \mathrm{pg} / \mathrm{mg})$ have consumed alcohol during the preceding months. ${ }^{12,21}$ The diagnostic power of hETG is not significantly influenced by age, gender, body mass index, tobacco smoke, hair color, or treatment of hair with commercial hair products, with the exception of bleaching and dying. ${ }^{28,34,35}$

The advantage of hETG in the initial screening of LTX candidates is that it is the only method that allows the retrospective detection of alcohol intake for 3 or even for up to 6 months. In the study by Sterneck et $\mathrm{al}^{12}$ in transplant candidates with alcoholic liver cirrhosis, alcohol intake was exclusively disclosed by hETG testing in $46 \%$ of patients, as all other alcohol markers (including CDT, methanol, etc) were tested negative. Alcohol abstention was disproved by hETG in as many as 23 (of a total of 63) patients with a negative urinary ETG result; these patients had apparently abstained from alcohol intake shortly prior to presentation. The same authors reported that there was no impact of liver function on $\mathrm{hETG}$ concentrations, and a specificity of $91 \%$ for hETG was calculated in patients with cirrhosis. ${ }^{12}$

Irrespective of the alcohol marker in use, an interdisciplinary approach to transplant candidates with an ALD engaging hepatologists, surgeons, and experts in psychosomatic medicine and addiction medicine is asked for. ${ }^{36,37}$ It is important 
for the clinical assessment to be able to grasp the different relevant aspects within the transplantation setting such as psychological comorbidities, individual stress factors, coping strategies, and specific needs. Therefore, the primary evaluation of a patient's situation in its entirety by an expert in psychosomatic medicine should remain the superordinate standard procedure. The decision to include a patient with ALD in the transplant list or exclude them from it should not be taken based on ETG measures alone. In some cases, even a deviation from the 6-month abstinence rule may be justified as proposed by others. ${ }^{37}$ Following the procedure suggested here, personal interview by a medical professional is placed in the center of decision making. Furthermore, the objective of the clinical evaluation is not only the detection of alcohol intake but also the definition of therapy options. It is a mistake in the context of LTX to overlook the fact that alcohol dependency is not a patient's fault but a disease that needs treatment.

Liver transplantation in patients with ALD is not more than a symptomatic therapy. Therefore, a psychotherapeutic attendance starting from the initial screening for eligibility and stretching out over the posttransplantation period is urgently needed. Therefore, future research should focus on developing not only reliable measures of alcohol consumption but also psychological interventions for patients with ongoing alcohol intake before LTX.

\section{Declaration of Conflicting Interests}

The author(s) declared no potential conflicts of interest with respect to the research, authorship, and/or publication of this article.

\section{Funding}

The author(s) received no financial support for the research, authorship, and/or publication of this article.

\section{References}

1. Watt KD, McCashland TM. Transplantation in the alcoholic patient. Semin Liver Dis. 2004;24(3):249-255.

2. Bhagat V, Mindikoglu AL, Nudo CG, Schiff ER, Tzakis A, Regev A. Outcomes of liver transplantation in patients with cirrhosis due to nonalcoholic steatohepatitis versus patients with cirrhosis due to alcoholic liver disease. Liver Transpl. 2009;15(12):1814-1820. doi:10.1002/lt.21927.

3. Burroughs AK, Sabin CA, Rolles K, et al. 3-month and 12-month mortality after first liver transplant in adults in Europe: predictive models for outcome. Lancet. 2006;367(9506):225-232.

4. Dom G, Wojnar M, Crunelle CL, et al. Assessing and treating alcohol relapse risk in liver transplantation candidates. Alcohol Alcohol. 2015;50(2):164-172. doi:10.1093/alcalc/agu096.

5. Faure S, Herrero A, Jung B, et al. Excessive alcohol consumption after liver transplantation impacts on long-term survival, whatever the primary indication. $J$ Hepatol. 2012;57(2):306-312. doi: 10.1016/j.jhep.2012.03.014.

6. Cuadrado A, Fábrega E, Casafont F, Pons-Romero F. Alcohol recidivism impairs long-term patient survival after orthotopic liver transplantation for alcoholic liver disease. Liver Transpl. 2005;11(4):420-426.
7. Dew MA, DiMartini AF, Steel J, et al. Meta-analysis of risk for relapse to substance use after transplantation of the liver or other solid organs. Liver Transpl. 2008;14(2):159-172. doi:10.1002/1t. 21278.

8. Bholah H, Bate J, Rothwell K, Aldersley M. Random blood alcohol level testing detects concealed alcohol ingestion in patients with alcoholic liver disease awaiting liver transplantation. Liver Transpl. 2013;19(7):782-783. doi:10.1002/lt.23664.

9. Erim Y, Böttcher M, Dahmen U, Beck O, Broelsch CE, Helander A. Urinary ethyl glucuronide testing detects alcohol consumption in alcoholic liver disease patients awaiting liver transplantation. Liver Transpl. 2007;13(5):757-761.

10. Allen JP, Wurst FM, Thon N, Litten RZ. Assessing the drinking status of liver transplant patients with alcoholic liver disease. Liver Transpl. 2013;19(4):369-376. doi:10.1002/1t.23596.

11. Hempel JM, Greif-Higer G, Kaufmann T, Beutel ME. Detection of alcohol consumption in patients with alcoholic liver cirrhosis during the evaluation process for liver transplantation. Liver Transpl. 2012;18(11):1310-1315. doi:10.1002/1t.23468.

12. Sterneck M, Yegles $M$, Rothkirch von $G$, et al. Determination of ethyl glucuronide in hair improves evaluation of long-term alcohol abstention in liver transplant candidates. Liver Int. 2013; 34(3):469-476. doi:10.1111/liv.12243.

13. Iasi MS, Vieira A, Añez CI, et al. Recurrence of alcohol ingestion in liver transplantation candidates. Transplant Proc. 2003;35(3): 1123-1124.

14. World Health Organization. International Statistical Classification of Diseases and Related Health Problems, 10th Revision (ICD-10). Geneva, Switzerland: WHO; 1992.

15. Erim Y, Möller E, Beckebaum S, Gerken G, Broelsch CE, Senf WE. Manualised group therapy concept for patients with alcoholic cirrhosis awaiting liver transplantation. Z Psychosom Med Psychother. 2006;52(3):243-258.

16. Twillman RK, Manetto C, Wellisch DK, Wolcott DL. The Transplant Evaluation Rating Scale. A revision of the psychosocial levels system for evaluating organ transplant candidates. Psychosomatics. 1993;34(2):144-153.

17. Johann B, Lorenzen J. Psychosomatic evaluation of liver transplantation patients. Practical use of the Transplant Evaluation Rating Scale. In: Johann B, Erhard J, eds. Psychosomatic Are of Transplantation Patients. Lengerich, Germany: Pabst Science Publishers; 1997:43.

18. Rothenhausler HB, Ehrentraut S, Kapfhammer HP. Psychosocial screening and selection of candidates for liver transplantation. Psychother Psychosom Med Psychol. 2003;53(9-10):364-375.

19. German Institute for Standardization. Web site. http://www.nqsz. din.de/cmd;jsessionid=IJ1LCCN4FKOPQELQOKS9Y3WY.2? level=tpl-art-detailansicht\&committeeid $=54739099 \&$ artid $=$ 77196483 \&languageid $=$ en $\&$ bcrumblevel $=2$. Published August 2005. Accessed January 3, 2015.

20. Society of Hair Testing 2012. Use of Alcohol Markers in Hair for Abstinence Assessment 2012 Consensus of the Society of Hair Testing. Web site. http://www.soht.org/images/pdf/ Use \%20of\%20Alcohol\%20Markers\%20in\%20Hair\%20for $\% 20$ Abstinence\%20Assessment\%202012.pdf. Published June 28, 2012. Accessed January 3, 2015. 
21. Crunelle CL, Yegles M, van Nuijs AL, et al. Hair ethyl glucuronide levels as a marker for alcohol use and abuse: a review of the current state of the art. Drug Alcohol Depend. 2014;134:1-11. doi: 10.1016/j.drugalcdep.2013.10.008.

22. Berlakovich GA, Soliman T, Freundorfer E, et al. Pretransplant screening of sobriety with carbohydrate-deficient transferrin in patients suffering from alcoholic cirrhosis. Transpl Int. 2004; 17(10):617-621.

23. Wurst FM, Wiesbeck GA, Metzger JW, Weinmann W. On sensitivity, specificity, and the influence of various parameters on ethyl glucuronide levels in urine-results from the WHO/ISBRA study. Alcohol Clin Exp Res. 2004;28(8):1220-1228.

24. Haller DL, Acosta MC, Lewis D, et al. Hair analysis versus conventional methods of drug testing in substance abusers seeking organ transplantation. Am J Transplant. 2010;10(5):1305-1311. doi:10.1111/j.1600-6143.2010.03090.x.

25. Stibler H, Borg S, Joustra M. A modified method for the assay of carbohydrate-deficient transferrin (CDT) in serum. Alcohol Alcohol Suppl. 1991;1:451-454.

26. Høiseth G, Morini L, Polettini A, Christophersen A, Mørland J. Ethyl glucuronide in hair compared with traditional alcohol biomarkers - a pilot study of heavy drinkers referred to an alcohol detoxification unit. Alcohol Clin Exp Res. 2009;33(5):812-816. doi:10.1111/j.1530-0277.2009.00900.x.

27. Kharbouche H, Steiner N, Morelato M, et al. Influence of ethanol dose and pigmentation on the incorporation of ethyl glucuronide into rat hair. Alcohol. 2010;44(6):507-514. doi:10.1016/j.alcohol. 2010.05.001.

28. Suesse S, Pragst F, Mieczkowski T, et al. Practical experiences in application of hair fatty acid ethyl esters and ethyl glucuronide for detection of chronic alcohol abuse in forensic cases. Forensic Sci Int. 2012;218(1-3):82-91. doi:10.1016/j.forsciint.2011.10.006.

29. Lees R, Kingston R, Williams TM, Henderson G, LingfordHughes A, Hickman M. Comparison of ethyl glucuronide in hair with self-reported alcohol consumption. Alcohol Alcohol. 2012; 47(3):267-272. doi:10.1093/alcalc/ags010.

30. Boscolo-Berto R, Favretto D, Cecchetto G, et al. Sensitivity and specificity of EtG in hair as a marker of chronic excessive drinking: pooled analysis of raw data and meta-analysis of diagnostic accuracy studies. Ther Drug Monit. 2014;36(5):560-575. doi:10. 1097/FTD.0000000000000063.

31. Kronstrand R, Brinkhagen L, Nyström FH. Ethyl glucuronide in human hair after daily consumption of 16 or $32 \mathrm{~g}$ of ethanol for 3 months. Forensic Sci Int. 2012;215(1-3):51-55. doi:10.1016/j. forsciint.2011.01.044.

32. Politi L, Zucchella A, Morini L, Stramesi C, Polettini A. Markers of chronic alcohol use in hair: comparison of ethyl glucuronide and cocaethylene in cocaine users. Forensic Sci Int. 2007;172(1):23-27.
33. Pragst F, Yegles M. Determination of fatty acid ethyl esters (FAEE) and ethyl glucuronide (EtG) in hair: a promising way for retrospective detection of alcohol abuse during pregnancy? Ther Drug Monit. 2008;30(2):255-263. doi:10.1097/FTD.0b013e $318167 \mathrm{~d} 602$.

34. Martins Ferreira L, Binz T, Yegles M. The influence of ethanol containing cosmetics on ethyl glucuronide concentration in hair. Forensic Sci Int. 2012;218(1-3):123-125. doi:10.1016/j.forsciint. 2011.10.015.

35. Morini L, Zucchella A, Polettini A, Politi L, Groppi A. Effect of bleaching on ethyl glucuronide in hair: an in vitro experiment. Forensic Sci Int. 2010;198(1-3):23-27. doi:10.1016/j.forsciint. 2009.11.005.

36. Addolorato G, Mirijello A, Leggio L, et al. Liver transplantation in alcoholic patients: impact of an alcohol addiction unit within a liver transplant center. Alcohol Clin Exp Res. 2013;37(9): 1601-1608. doi:10.1111/acer.12117.

37. Testino G, Burra P, Bonino F, et al. Acute alcoholic hepatitis, end stage alcoholic liver disease and liver transplantation: an Italian position statement. World J Gastroenterol. 2014;20(40): 14642-14651. doi:10.3748/wjg.v20.i40.14642.

\section{Author Biographies}

Mingo Beckmann is a Doctor of psychology. Scientific focus of her work is psychooncology, psychosomatic evaluation of transplant patients and living organ donors.

Georgios Paslakis is an assistant professor, specialist psychiatrist. Work focus: neuroendocrinology, eating disorders.

Michael Böttcher, PhD, is a Doctor of biology and head of the Department of Toxicology in "MVZ Labor Dessau GmbH".

Anders Helander, PhD, Adjunct professor at Karolinska Institute, Department of Laboratory Medicine. Anders Scientific focus are Development and application of improved laboratory testing for alcohol and drugs of abuse.

Yesim Erim, MD, is a Head of the Department of Psychosomatic Medicine and Psychotherapy and teaching professor at the University Hospital of Erlangen. Professor Erim was the Principal Investigator on the Cooperative Study for the Optimization of the Psychiatric Outpatient Services for Immigrants in North Rhine-Westphalia, including nine psychiatric hospitals in the region supported by the local administration (Landschaftsverband) from 2006 to 2013. Her published works focus on the prevalence of mental disorders in ethnic groups, culturally adapted psychotherapy, as well as the translation and validation of questionnaires. Another focus of her work is psychotherapeutic interventions with the physically ill. 